\title{
Hand-assisted laparoscopic splenectomy for giant spleens
}

\author{
E. C. Borrazzo, J. M. Daly, K. P. Morrisey, E. Fischer, M. Belmont, N. J. Hogle, D. L. Fowler
}

[Surg Endosc (2003) 17: 918-920, DOI: 10.1007/s00464-002-8946-z]

The artwork for Fig. 1 was not published in the online version of this article. The figure is reproduced with its legend here. The publisher regrets the error.

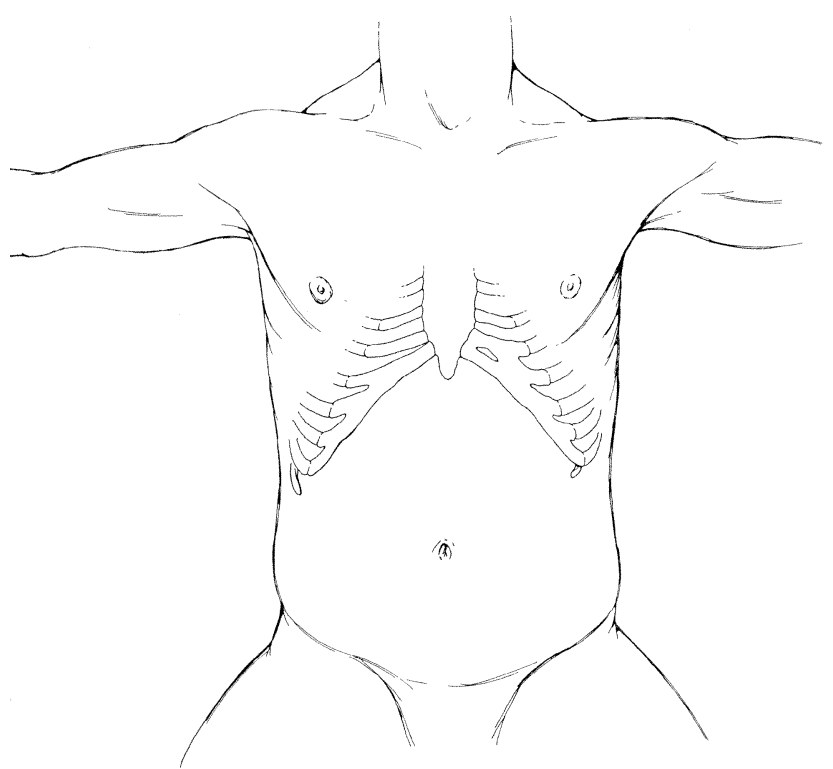

Fig. 1. Schematic of the port placement showing the incision in the midline upper abdomen for the hand-assist device, a lower midline and left-lateral incision for each 5-mm trocar, and a left lower abdominal incision lateral to the rectus muscle for a $12-\mathrm{mm}$ trocar. 